\title{
Sistem Informasi Keuangan Pada Kantor Notaris Yunita Kadir, S.H., M.Kn Luwuk Banggai
}

\author{
Trisno Wibowo. $\mathrm{K}^{1}$, Feni Susanti Nabeng ${ }^{2}$ \\ ${ }_{1,2}$ AMIK Luwuk Banggai \\ Luwuk, Kabupaten Banggai 94711 - Sulawesi Tengah \\ e-mail: trisnowibowo@amik-nurmal.ac.id, feninabeng094056@gmail.com
}

\begin{abstract}
Abstrak - Beberapa masalah yang diperoleh dalam melakukan penelitian diantaranya : beberapa perhitungan terhadap transaksi dilakukan secara manual, dalam penelitian ini pengolahan data transaksi yang dilakukan secara manual tidak menjadi masalah, tetapi yang menjadi masalah adalah banyaknya transaksi yang ada diolah menggunakan sistem pencatatan manual dan hal tersebut akan menghambat dan memperlambat pekerjaan, karena banyaknya proses transaksi yang harus di input, serta tahapan-tahapan yang harus dibuat, jika menggunakan pencatatan secara manual. Metode yang digunakan dalam penelitian ini adalah metode kualitatif dengan teknik pengumpulan data menggunakan tiga cara yaitu metode observasi, metode wawancara dan metode pustaka. Serta dalam perancangan menggunakan alat perancangan seperti diagram konteks, DFD, ERD dan lainnya serta perancangan sistem yang diintegrasikan dengan database. Beberapa kesimpulan yang dapat disampaiakn, yaitu sebagai berikut: Sistem Informasi Keuangan Pada Kantor Notaris Yunita Kadir, S.H., M.Kn dapat berjalan dan dioperasikan dengan baik, Dengan adanya Sistem Informasi Keuangan ini dapat memberikan informasi keuangan secara baik, cepat, tepat dan efisien dan Sistem informasi ini juga dapat membantu proses transaski uang masuk dan uang keluar pada Kantor Notaris Yunita Kadir, S.H., M.Kn.
\end{abstract}

Kata kunci: Sistem Informasi, Notaris, Keuangan, PHP, Web

\section{Pendahuluan}

Sistem informasi berbasis komputer kini banyak diidamkan oleh banyak orang, bahkan menjadi kebutuhan primer. Sistem informasi digunakan untuk mengumpulkan, memproses dan memberikan informasi untuk membantu pengambilan keputusan[1]. Banyak bidang kehidupan kita menggunakan sistem informasi berbasis komputer untuk menyederhanakan pekerjaan. Mulailah dengan bisnis, pendidikan, pemerintahan, kesehatan, dll[2].

Kantor Notaris Yunita Kadir, S.H., M.Kn misalnya, saat ini tengah melakukan ujicoba untuk migrasi proses pengelolaan dari konvensional menjadi tersistem informasi, terutama dalam hal laporan transaksi keuangan yang ada. Kantor Notaris Yunita Kadir memiliki beragam layanan dengan biaya layanan yang berbeda - beda, sekaligus layanan - layanan tersebutlah yang menjadi sumber pemasukan dari Kantor Notaris Yunita Kadir.

Beberapa masalah yang penulis dapatkan dalam melakukan penelitian diantaranya : 1) beberapa perhitungan terhadap transaksi dilakukan secara manual, 2) Dalam penelitian ini pengolahan data transaksi secara manual tidak menjadi masalah, namun yang menjadi permasalahan adalah banyaknya transaksi yang diproses menggunakan sistem pencatatan manual, 3) Hal ini akan menghambat dan memperlambat pekerjaan karena banyak proses transaksi dan berbagai tahapan yang harus dimasukkan dan diolah secara bersamaan.

\section{Tinjauan Pustaka}

Sistem adalah sekumpulan elemen yang saling berhubungan atau terintegrasi yang dirancang untuk mencapai tujuan dari elemen-elemen penyusun sistem yaitu tujuan, masukan, keluaran, proses, mekanisme, pengendalian, dan umpan balik. Selain itu, sistem juga berinteraksi dengan lingkungan dan memiliki batasanbatasan[3]. Ladjamudin (2008) berpendapat informasi adalah data yang telah diolah menjadi bentuk yang lebih berarti dan berguna bagi penerimanya untuk mengambil keputusan masa kini maupun masa yang akan datang[4]. Sistem informasi adalah sistem dalam organisasi yang menjumlahkan kebutuhan pemrosesan transaksi harian untuk mendukung pengelolaan fungsi operasional organisasi dan kegiatan strategis organisasi, sehingga dapat memberikan kepada pihak eksternal tertentu informasi yang dibutuhkan untuk pengambilan keputusan[5].

Dr. Wastam Hidayat (2018: 2) menjelaskan bahwa laporan keuangan merupakan informasi yang menggambarkan status keuangan suatu perusahaan, dan informasi tersebut dapat digunakan untuk menggambarkan kinerja keuangan perusahaan[6]. Laporan keuangan merupakan alat yang sangat penting untuk memperoleh informasi mengenai status keuangan dan kinerja perusahaan, oleh karena itu laporan keuangan diharapkan dapat membantu pengguna dalam mengambil keputusan keuangan dan ekonomi[7].

Menurut Jogiyanto (2014), DFD merupakan ide dari suatu bagan untuk mewakili arus data dalam suatu 
sistem bukanlah hal yang baru. Pada tahap analisis, pengunaan notasi ini sangat membantu sekali di dalam komunikasi dengan pemakai sistem untuk memahami sistem secara logika. Diagram yang menggunakan notasi-notasi ini untuk menggambarkan arus dari data sistem sekarang dikenal dengan nama diagram arus data (data flow diagram atau DFD)[8].

\section{Metode Penelitian}

Pendekatan metode Penelitian yang diguanakan adalah pendekatan kualitatif, yang merupakan strategi inkuiri yang menekankan pada pencarian makna, pemahaman, konsep, ciri, gejala, simbol, dan deskripsi fenomena; fokus, multi metode, natural dan komprehensif; menggunakan beberapa metode untuk mengedepankan kualitas, dan Bentuk naratif disajikan. Di sisi lain, secara sederhana dapat dikatakan bahwa tujuan penelitian kualitatif adalah untuk menemukan jawaban atas fenomena atau permasalahan dengan menggunakan metode kualitatif untuk mengaplikasikan prosedur ilmiah secara sistematis[6]. Sedangkan untuk pengumpulan datanya menggunakan beberapa metode :

1. Observasi, dalam metode ini peneliti melakukan pengamatan secara langsung dengan turun langsung ke lokasi penelitian, langsung mengamati bagaimana prosedur dan mekanisme penyambungan pelanggan baru.

2. Wawancara, adalah Teknik mengumpulkan data yang dilakukan dengan melakukan wawancara secara langsung kepada narasumber yang memiliki jabatan strategis pada objek penelitian.

3. Studi Pustaka, merupakan metode pengumpulan data melalui referensi literatur buku, jurnal, artikel ilmiah tentang perancangan system, website, database dll.

\section{Hasil dan Pembahasan}

Perancangan sistem adalah tata cara dan proses merancang, membangun dan membentuk sebuah model dan rancangan dari suatu sistem nyata dalam bahasa formal tertentu. Untuk memodelkan suatu sistem, maka kita perlu tahu gambaran permasalahan yang ada serta hubungan antar komponen, variabel dan parameter parameter sistemnya. Sehingga agar kita dapat merancangankan suatu desain dari sebuah sistem.

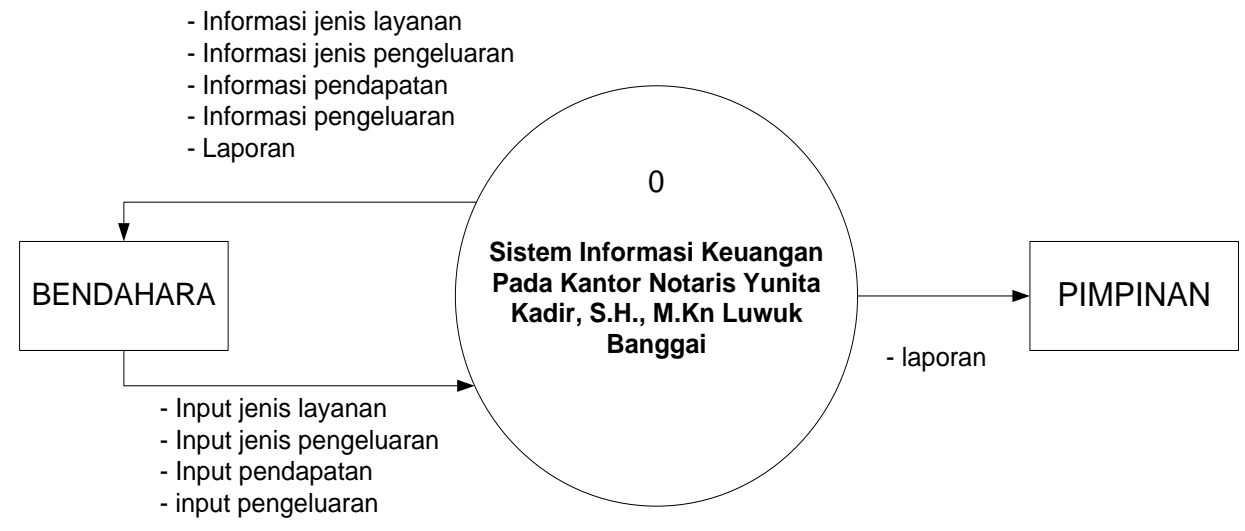

Gambar 1. Diagram Konteks 


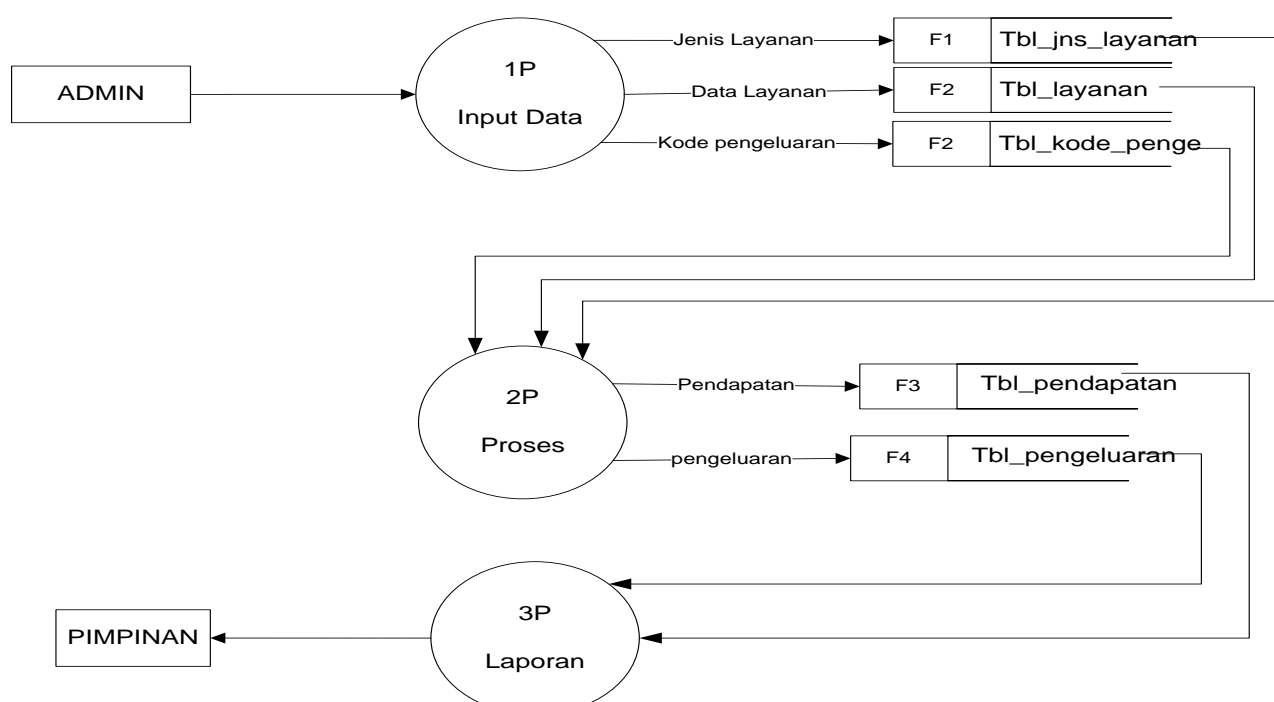

Gambar 2. Diagram Zero

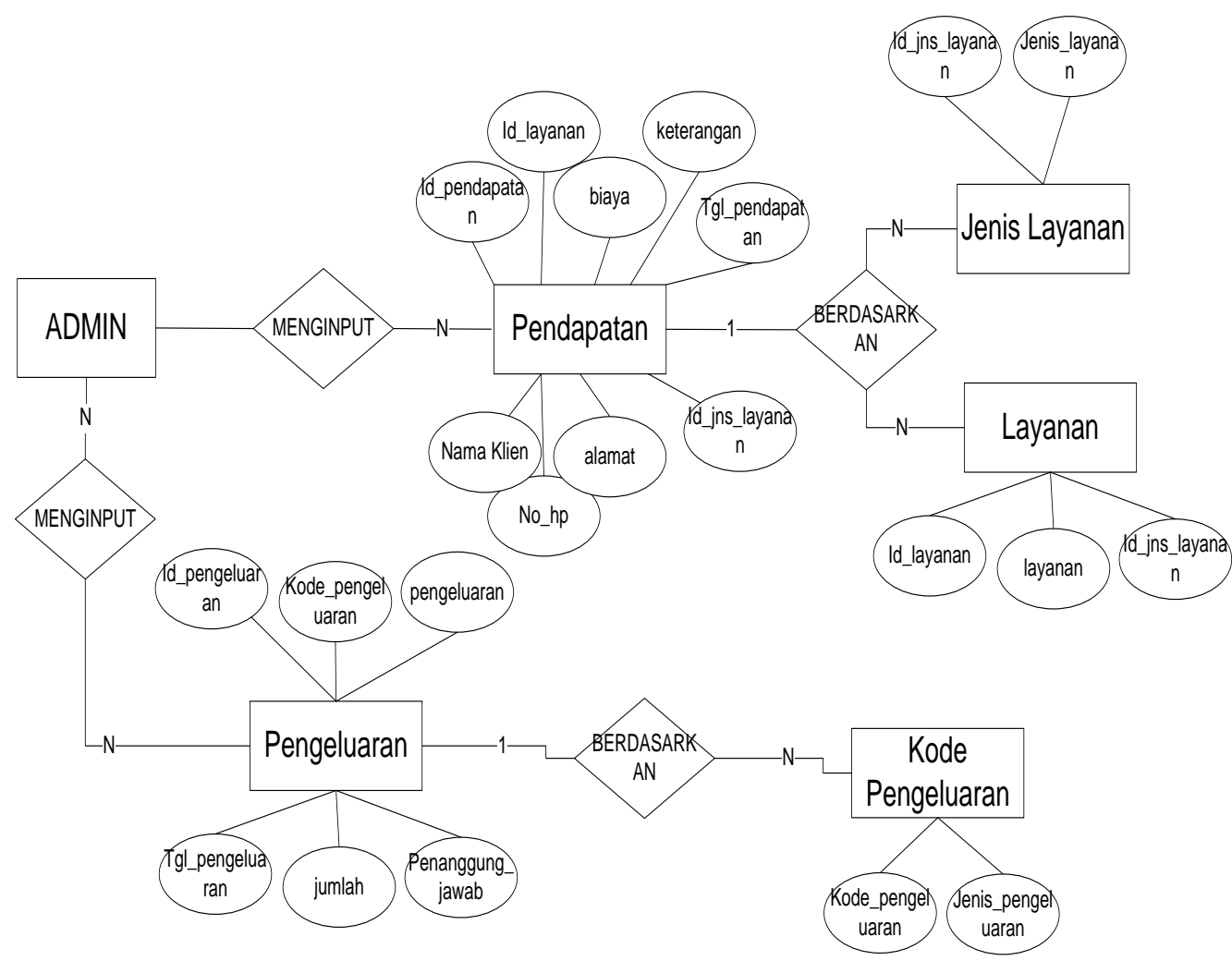

Gambar 3. ERD

Tabel 1. Tabel Jenis Layanan

\begin{tabular}{|l|c|c|c|}
\hline \multicolumn{1}{|c|}{ Nama Item } & Data Type & Size & Field kunci \\
\hline Id_jenis_layanan & int & 1 & Primary Key \\
\hline Jenis_layanan & varchar & 30 & \\
\hline
\end{tabular}


Tabel 2. Tabel Pendapatan

\begin{tabular}{|l|c|c|l|}
\hline \multicolumn{1}{|c|}{ Nama Item } & Data Type & Size & Field kunci \\
\hline Id_pendapatan & int & 10 & Primary Key \\
\hline Id_layanan & int & 3 & \\
\hline biaya & int & 12 & \\
\hline keterangan & varchar & 50 & \\
\hline Tgl_pendapatan & varchar & 16 & \\
\hline nama_klien & varchar & 100 & \\
\hline no_hp & varchar & 12 & \\
\hline alamat & text & & \\
\hline Id_jenis_layanan & int & 1 & \\
\hline
\end{tabular}

Tabel 3. Tabel Pengeluaran

\begin{tabular}{|l|c|c|l|}
\hline \multicolumn{1}{|c|}{ Nama Item } & Data Type & Size & Field kunci \\
\hline Id_pengeluaran & int & 10 & Primary Key \\
\hline Kode_pengeluaran & varchar & 20 & \\
\hline pengeluaran & varchar & 100 & \\
\hline Tgl_pengeluaran & varchar & 16 & \\
\hline jumlah & int & 12 & \\
\hline penanggungjawab & varchar & 50 & \\
\hline
\end{tabular}

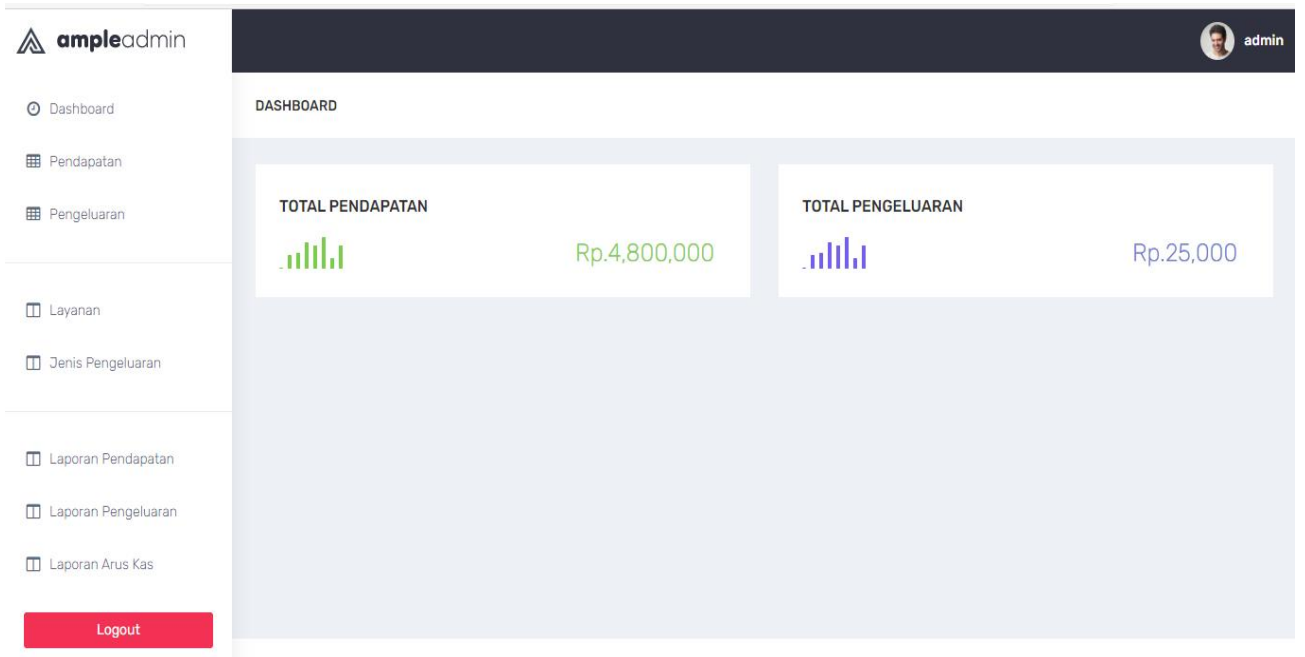


Gambar 4. Halaman Dashboard

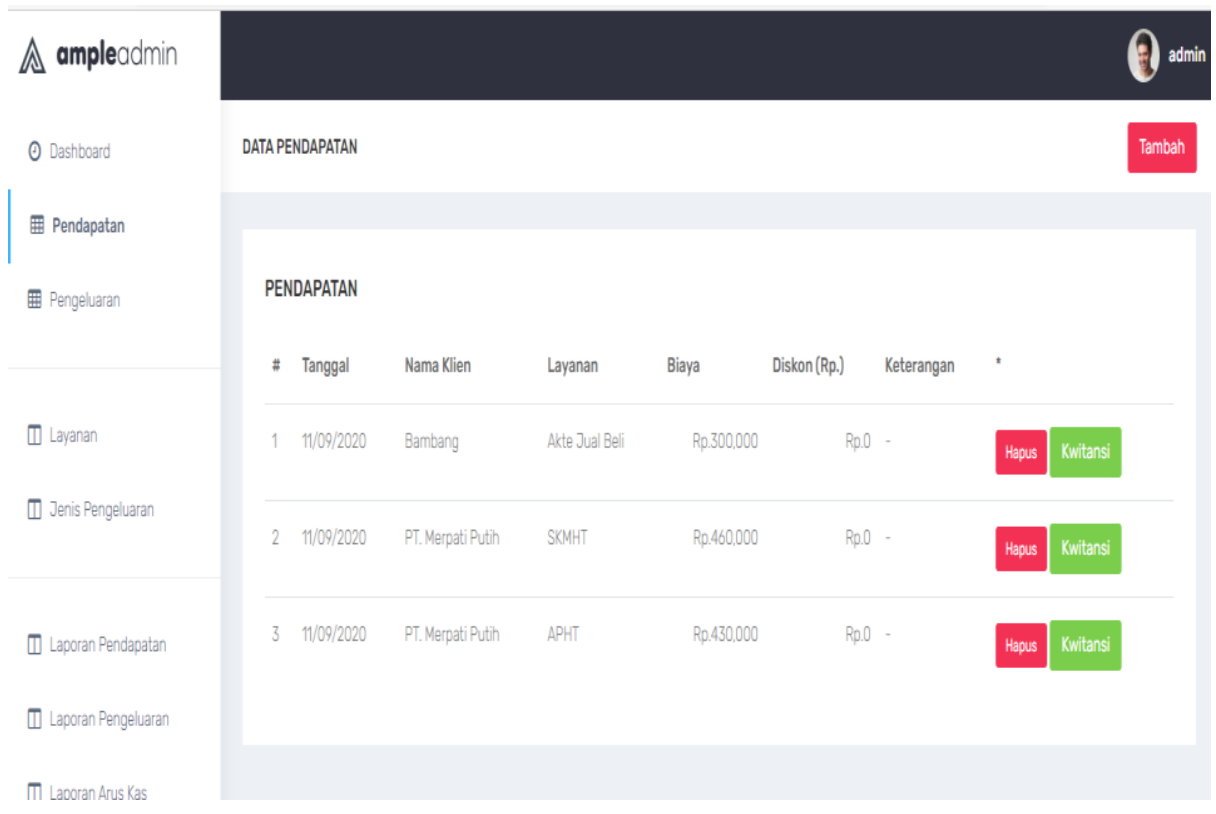

Gambar 5. Halaman Pendapatan

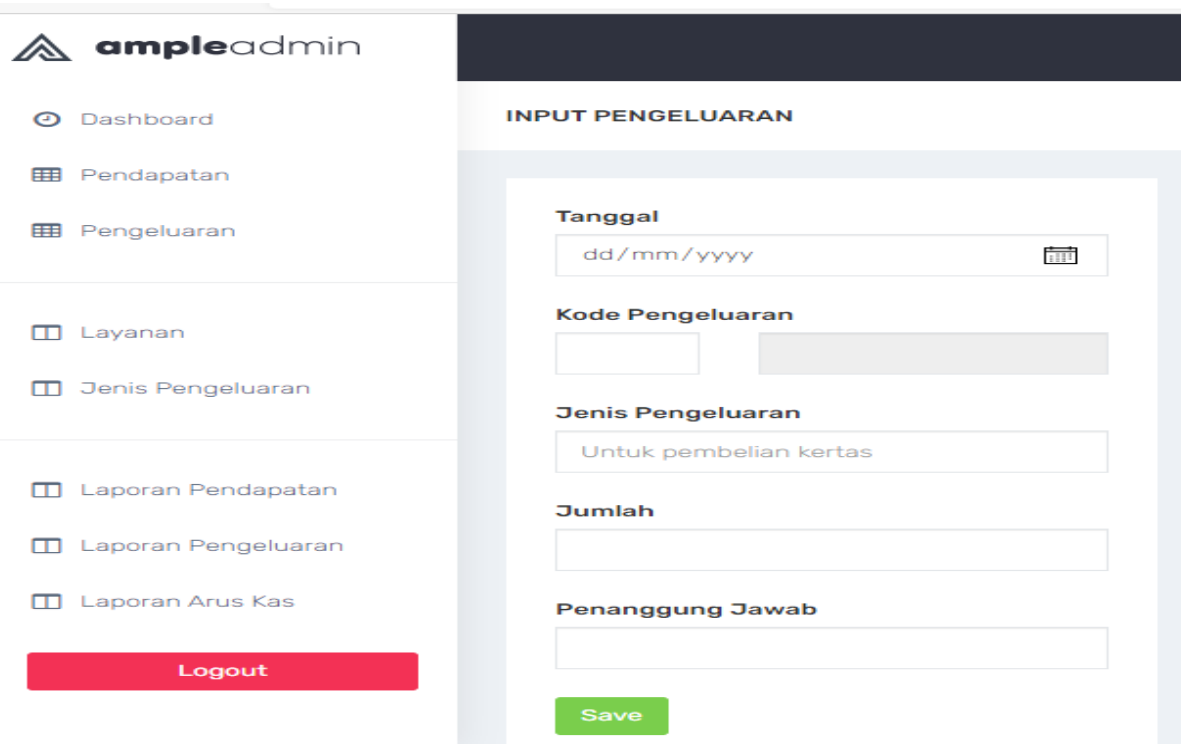

Gambar 6. Halaman Input Pengeluaran 


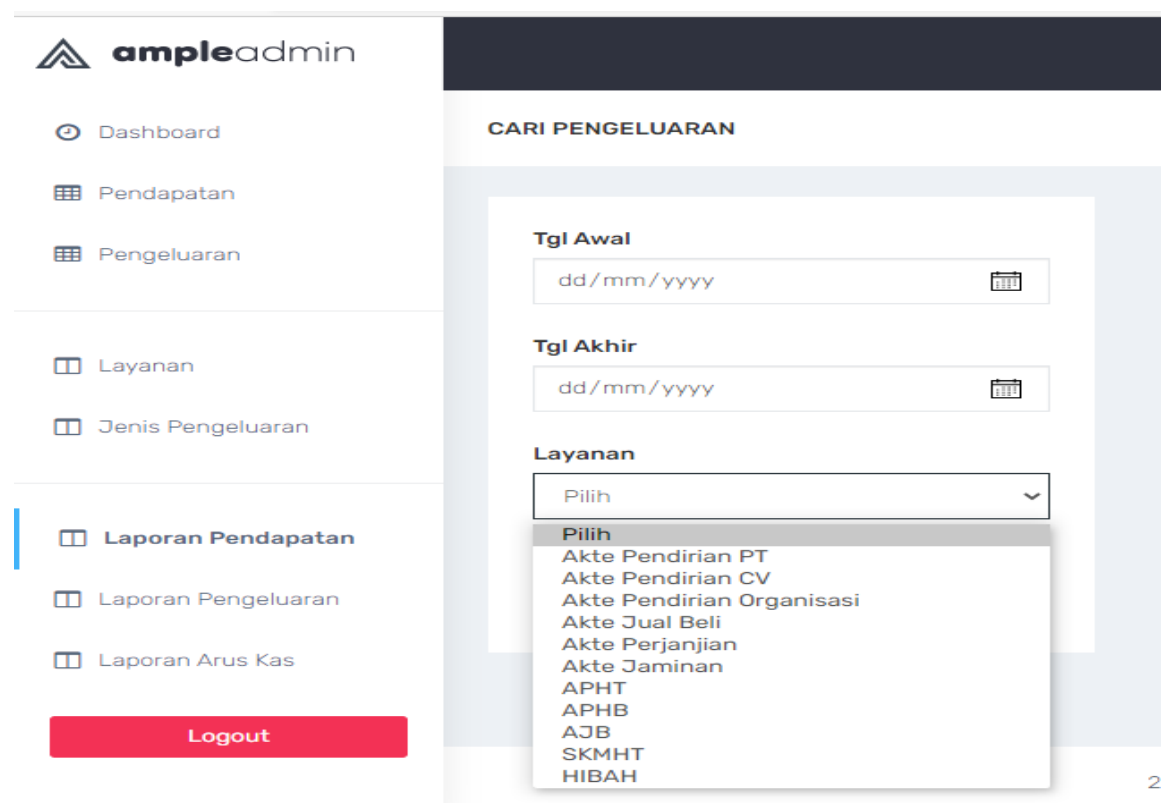

Gambar 7. Halaman Pendampatan

\begin{tabular}{|c|c|c|c|}
\hline \multicolumn{4}{|c|}{$\begin{array}{c}\text { YUNITA KADIR, S.H., M.Kn. } \\
\text { NOTARIS \& PPAT } \\
\text { LAPORAN ARUS KAS }\end{array}$} \\
\hline \multicolumn{4}{|l|}{ PEMASUKAN } \\
\hline Akte Pendirian PT & & Rp. 0 & \\
\hline Akte Pendirian CV & & Rp. 0 & \\
\hline Akte Pendirian Organisasi & & Rp. O & \\
\hline Akte Jual Beli & & Rp. 300,000 & \\
\hline Akte Perjanjian & & Rp. 0 & \\
\hline Akte Jaminan & & Rp. 0 & \\
\hline APHT & & Rp. $1,500,000$ & \\
\hline APHB & & Rp. 0 & \\
\hline AJB & & Rp. 0 & \\
\hline SKMHT & & Rp. $1,000,000$ & \\
\hline \multirow[t]{2}{*}{ HIBAH } & & Rp. 0 & \\
\hline & Total & & Rp. $2,800,000$ \\
\hline \multicolumn{4}{|l|}{ PENGELUARAN } \\
\hline ATK & & Rp. O & \\
\hline Pembelian Sarana dan Prasarana & & Rp. 0 & \\
\hline Gaji, BPJS & & Rp. 0 & \\
\hline Pajak & & Rp. 0 & \\
\hline & Total & & Rp.0 \\
\hline SALDO & & & Rp. $2,800,000$ \\
\hline
\end{tabular}

Gambar 8. Laporan Arus Kas

\section{Kesimpulan}

Berdasarkan pembahasan yang telah dipaparkan sebelumnya, serta proses penerapannya terhadap sistem yang telah dibuat, maka dapat di tarik beberapa kesimpulan, yaitu sebagai berikut:

1. Sistem Informasi Keuangan Pada Kantor Notaris Yunita Kadir, S.H., M.Kn dapat berjalan dan dioperasikan dengan baik.

2. Dengan adanya Sistem Informasi Keuangan ini dapat memberikan informasi keuangan secara baik, cepat, tepat dan efisien.

3. Sistem informasi ini juga dapat membantu proses transaski uang masuk dan uang keluar pada Kantor Notaris Yunita Kadir, S.H., M.Kn.

\section{Daftar Pustaka}

[1] D. Satria, Zulfan, S. Yana, and Julijar, "Perancangan SIstem Informasi Manajemen Pembelian dan Penjualan Komoditas Perkebunan Masyarakat Pada UD.Bintang Baru," J. Manaj. dan Akunt., vol. 4, no. 
1, pp. 39-47, 2018.

[2] M. Munawir et al., "Penerapan Sistem Informasi Pendataan Penerima Dana Program Keluarga Harapan pada Gampong Beurawe Kecamatan Kuta Alam berbasis Web GIS," J. Serambi Eng., vol. 6, no. 3, 2021.

[3] Z. Zulfan, B. Bahagia, H. Ahmadian, and D. Satria, "Sistem Informasi Data Korban Kebencanaan Berbasis Web," in Prosiding Seminar Nasional USM, 2017, vol. 1, no. 1.

[4] S. Shopalazuli, B. Baihaqi, and E. Erdiwansyah, "Sistem Informasi Pengambilan Keputusan Penerima Rehab Rumah Menggunakan Metode Weighted Sum Model (WSM) Pada Desa Bira Lhok Kecamatan Montasik," J. Nas. Komputasi dan Teknol. Inf., vol. 4, no. 6, pp. 405-414, 2021.

[5] M. F. Setiawan, M. N. Witama, and R. Hikmah, "Perancangan Sistem Pengolahan Data Produksi Konveksi Berbasis Java Pada CV Nirwana Bunga Abadi," J. Nas. Komputasi dan Teknol. Inf., vol. 3, no. 3, pp. 202-208, 2020.

[6] S. Wijayanto, "Analisa perancangan model sistem monitoring, pencatatan dan pengiriman hasil produksi truk dengan Remote File Transfer System (RFTS) pada perusahaan XYZ menggunakan metode System Development Life Cycle," J. Nas. Komputasi dan Teknol. Inf., vol. 3, no. 1, pp. 1-8, 2020.

[7] A. A. F. Amarta and I. G. Anugrah, "Implementasi Agile Scrum Dengan Menggunakan Trello Sebagai Manajemen Proyek Di PT Andromedia," J. Nas. Komputasi dan Teknol. Inf., vol. 4, no. 6, pp. 528-534, 2021.

[8] Suhartini, M. Sadali, and Y. K. Putra, "Sistem Informasi Berbasis Web Sma Al- Mukhtariyah Mamben Lauk Berbasis Php Dan Mysql Dengan Framework Codeigniter,” vol. 3, no. 1, pp. 79-84, 2020. 